\title{
TMT Diversity, Decision Quality and Service Sector Firm Performance: A Research Agenda
}

\author{
Beatrice A. Oduor ${ }^{1} \&$ James M. Kilika ${ }^{1}$ \\ ${ }^{1}$ Department of Business Administration, School of Business, Kenyatta University, Kenya \\ Correspondence: James M. Kilika, Lecturer, Department of Business Administration, School of Business, Kenyatta \\ University, Kenya.
}

Received: March 28, 2018

Accepted: April 11, 2018

Online Published: April 26, 2018

doi:10.5430/jms.v9n2p34

URL: https://doi.org/10.5430/jms.v9n2p34

\begin{abstract}
This paper reviews the extant theoretical and empirical literatures on TMT Diversity, Decision Quality and firm performance in a service sector setting. The constructs are traced from their theoretical roots and their nature, characteristics and operational descriptions provided. The emerging gaps in knowledge emanating from the theoretical and empirical literature are summarized and a theoretical model linking the constructs proposed. The paper makes several propositions and calls on future research to develop data collection tools for measuring the constructs in the study in empirical work.
\end{abstract}

Keywords: TMT diversity, decision quality, firm performance, service sector, institutional environment

\section{Introduction}

Over the years, Top Management Team (TMT) diversity has continued to be an area of interest to strategic management researchers (Hambrick \& Mason, 1984). According to Kor (2006), TMTs have the responsibility of making the general strategic decisions, as the members establish achievable objectives and design a method to be employed to realize the objectives of the organization. The responsibility of the top management lies in the operations of the firm and in ensuring that the firm achieves sustainable competitive advantage (Finkelstein \& Hambrick, 1996; Hambrick \& Mason, 1984). The importance of TMT members lies on the responsibility they have in the organizations when making strategic decisions (Hambrick, 1994).

The extant literature focusing on TMT diversity and firm performance link is based on the assumption that demographic diversity is a prerequisite for the increased cognitive diversity, leading to the improvement of decision quality and ultimately resulting into firm performance. As part of their everyday work, TMTs have to make decisions on organizational issues and assist in resolving strategic, structural and work flow problems. The executive management responsibility is to engage in ratifying longer range decisions which set the firm's direction (Floyd \& Lane, 2000). The effectiveness of the firms strategic decisions mainly depends on an integrated decision making framework capable of responding to the issues facing the firm through an incorporated broad range information to be considered during the decision making process (Hitt \& Collins, 2007).

Daft (2010) defines firm performance as an efficient and effective way of an organization to optimally exploit its resources of knowledge, people, and raw materials so as to attain its objectives. Flapper, Fortuin and Stoop (1996) describe performance as a process of attaining effective organizational objectives. The importance of top management teams as a determinant of firm performance continues to be the focus of strategic management researchers (Carson, 2004). As markets continue to expand, organizations need to diversify with respect to their employee's characteristics (Morison, 1992). The cognitive benefits of having a diverse group originates from the impact of diversity on creativity and requisite variety research (Hoffman \& Maier, 1961).

Even though Top management teams have continued to diversify in numerous dimensions, the implications of the TMT on performance have not been proven in strategic management literature (Nielsen \& Nielsen, 2012). Hambrick and Mason (1984) stated that the characteristics and actions of the top management team members are reflected in the performance of the organization. Mutuku, K'Obonyo and Awino (2013) defined TMT diversity in terms of the personality differences expressed in human beings. It has been classified in many categories, among them demographic and mental diversity. Demographic diversity focuses on characteristics such as age, gender, nationality 
and race which are right attributes of measuring individuals while the cognitive diversity focuses more on attitude and the normative differences between individuals (Mutuku, Awino \& Nzulwa, 2014).

Hitt and Collins (2007), pointed that effective decision processes for firms operating in competitive environments are those drawn from a diversity of backgrounds considering the several factors namely customers wants, readiness to new markets opportunity, operative work practices, reasonable engagement and vital resources. Therefore, knowledge diversity plays a key role in creating knowledge-based resources necessary for a sustainable competitive advantage (Anand, Glick, \& Manz, 2002; Hambrick, 2007).

The service sector places a greater emphasis on the role of human capital in the organization especially in cases where customized services are built around the tacit knowledge of the organization's employees. Hence, it can be stated that the service sector organizations are not necessarily physical in nature but are focused on how knowledge is shared within an organization (Cobb, 2004). The service sector is growing throughout the world and in every developed and developing country with clear manifestations of an entrepreneurial character being evident in this sector (Rodie \& Martin, 2001; Sawyer, 2002). Sawyer (2002) states that service sector organizations often deal with concepts and ideas as opposed to tangible products, and they need to develop tools, strategies, and solutions that can help them to defend their existing business and find new ways of utilizing their knowledge to grow the business

\subsection{Statement of the Problem}

Top management Teams represent a dominant coalition of the firm that has a significant influence on how the firm should refocus to stay at a competitive position within the industry. The extant literature on TMT characteristics shows that there has been a lot of research done in various aspects for theorizing purposes (Muchemi, 2012; Marimuthu \& Kolandaisamy, 2009, Homberg \& Bui, 2013, Mutuku, Awino \& Nzulwa, 2014). Hambrick and Mason (1984) studied the top management team under demographic characteristics of age, functional background, education and tenure, which paved the way to tackle diversity within the top management and its influence on firm performance which has been associated with the upper echelons theory.

Although the relationship between TMT characteristics and performance has attracted considerable research attention, several scholars (Irungu, 2007; Marimuthu \& Kolandaisamy, 2009; Letting et al., 2012) have reported mixed results. Irungu (2007) established that the influence of TMT characteristics on performance varies from one sector to another. On the other hand, Marimuthu and Kolandaisamy (2009) using demographic dimensions of TMT characteristics later found that TMT diversity is not relevant in explaining performance. In addition, the existence of cognitive factors such as sub-groups or individuals with diverse views and beliefs within TMT may influence the connection between TMT characteristics and firm performance (Michel \& Hambrick, 1992). The findings so far, cannot be generalized because of the noted inconsistencies. In an attempt to understand the importance of the TMT role especially in terms of diversity, previous studies have looked into different types of TMT diversities such gender, age, educational background, tenure, functional responsibility as well as working and industry experience (Salleh, Yusoff \& Saad,2015; Homberg \& Bui,2013; Manolova \& Manev, 2006;Talke, Salomo \& Kock, 2011). However, these studies have assessed the influence of different aspects of diversity separately as independent variables and in western context settings. Thus, these previous attempts face limitations that call for scholars to examine the theoretical and conceptual bases upon which the previous researches have been conceptualized and mounted. It is from such an observation that the authors identified the need to examine the extant literature with a view to highlighting the current understanding, theoretical base and state of empirical work on the constructs of TMT Diversity, Decision Quality and service sector firm performance.

The purpose of this paper therefore is to review the extant theoretical and empirical literature on the constructs of TMT diversity, decision quality and service sector firm performance as well as to identify both the theoretical and empirical gaps with a view to proposing a theoretical model to address the identified gaps. The objectives of the study are; to review the theoretical and empirical literature on the constructs of TMT diversity, decision quality and service sector firm performance; to identify the emerging theoretical and empirical gaps that form the basis for future research on TMT diversity, decision quality and service sector firm performance. Lastly, the paper proposes a theoretical model for responding to the theoretical and empirical gaps on TMT diversity, decision quality and service sector firm performance.

The study contributes to the theoretical body of knowledge by describing the strategic management phenomenon involving TMT diversity, decision quality and service industry performance. The proposed theoretical model will form the basis for informing and guiding future research in strategic management discipline and build a repertoire of knowledge to management practitioners. The work in the paper expands the current scope in terms of the theoretical underpinnings whereby the phenomenon is described from not only a strategic management lens but also from both 
behavioural and marketing perspectives and thus enriching the diversity of theoretical base that informs understanding of the phenomenon of firm strategic behaviour that relies on TMT Diversity, Decision quality and from performance.

\section{Review of Literature}

In response to the study objectives, the paper first presents a summary of the conceptual literature on the constructs of TMT diversity, decision quality and service sector firm performance. This is followed by the applicable theoretical review on the main theories upon which the constructs are anchored.

\subsection{Conceptual Review}

\subsubsection{Top Management Team Diversity}

Hambrick and Mason (1984), state that the influence of top management is not always the decision of one person but rather the entire top management team (TMT) responsibility. Therefore, top managers have the responsibility of making decisions which are in line with cognitive ability, which is acquired through education, functional background, values and experience (Smith, 1994). The psychological and demographic characteristics of the upper echelons are composed of a cognitive base, values, age, functional tracks, career experiences, social economic roots, education, financial position and group characteristics. The actions and decisions adopted by the top managers are highly influenced by the top manager's characteristics (Hambrick \& Mason, 1984). Hambrick (2007) updated the upper echelons theory and concluded that the bottom line of the upper echelons theory is linked to the values, experience and the top manager's personalities while doing the job. With such characteristics in place, the manager's interpretation and decision choice are guided by those characteristics.

Top management team (TMT) diversity is referred to as the distributional differences amongst the top management team members with respect to a common attribute. Top management team (TMT) diversity is referred to as the distributional differences amongst the top management team members with respect to a common attribute. The main objective of TMT at corporate level of the organization is to give advice on the decisions to be taken, the best directions to be taken on the strategies and how resource allocation on different projects should be done. TMT is a subsection of employees since TMT members have a constant contact with employees and the external environment of the organization.

TMT demographic diversity is defined as the differences in top management team members with respect to their demographics such as tenure, age, education level, and functional background (Lok, Rhodes, Sadeghinejad \& Najmaei, 2016). A review of the extant literature indicates that there are several dimensions of diversity that have been discussed as part of TMT. These are functional diversity, educational diversity, TMT average tenure and age diversity (Jackson, 1995). According to Gunderson and Sutcliffe (2002) a functionally diverse team is composed of senior executives with a limited knowledge and skills in their operational areas. This is reflected in the specialist skills that the top managers possess out of the many years spent on their professional career. An organization with a functionally diverse TMT will tap a range of knowledge, skills and expertise generated from a rich set of cognitive resources.

Educational Diversity is based on the assumption that TMTs with high level of education will benefit the organization. A closer examination reveals that TMTs with high level of education for example doctorate degree is not a guarantee of the benefits to the organization. The organization can be confined and limited to the innovative and creative ability due to the TMT members having a uniform cognitive structure and mental maps brought about by the high educational level. The resemblance in information processing and decision-making obtained from similar training and experience might prevent the organization from realizing innovative solutions.

Tenure is considered to be a key determinant of a group process. Stability, superior performance and reduced conflicts are linked to increased tenure (Katz, 1982). Cognitive structures and social cohesion of the top management team are linked to those managers with a long tenure (Michael and Hambrick, 1992). The characteristics of the TMT can be improved through socialization leading to better performance (Carroll \& Harrison, 1998, Smith et al. 1994).

\subsubsection{Decision Quality}

Frederickson and Mitchell (1984) describe strategic decision quality by using comprehensive and extensive measures of the outcome of decision quality. A comprehensive decision is one that seeks to explain how options have been evaluated and assessed on the extent to which the decision will impact the performance of a firm (Carmeli, Sheaffer \& Halevi, 2009). The decision quality can be defined as the extent to which the decisions have been realistic for a period of three years. In order to realize or fail to realize decision quality in the organization, alternative options should be 
evaluated during the decision making process. High or low level of extensiveness during the decision making process is operationalized under the realistic or unrealistic strategic decisions, for example the extent to which the top management as the decision makers of the organization have extensively considered and assessed the opportunities and threats the organization is likely to encounter in the business environment (Miller \& Cardinal, 1994).

Diversity is a valuable aspect of decision quality because it empowers group's cognitive ability leading to effective decisions. In order to survive the ever changing competitive environment, managers need to promptly equip themselves with adequate information and transform it into action. In producing an effective and innovative solution, studies show that decision comprehensiveness and speed can coexist and supplement one another (Andersen, 2004; Eisenhardt \& Bourgeois, 1988).

\subsubsection{Service Sector Context}

The service sector emphasizes the role of human capital in the organization. Especially customized services are built around the tacit knowledge of the organization's employees. Hence, it can be stated that the service sector organizations are not necessarily physical in nature but it is focused on how knowledge is shared within an organization (Cobb, 2004). Profound changes in competitive environments and in customer values have resulted in services becoming the central focus of corporate strategies and operational agendas for most organizations in the world. The challenge for the service sector is to implement strategies effectively and cost-efficiently (Vandermerwe, Lovelock \& Taishoff, 1994). The most commonly cited unique characteristics of services are intangibility (services are non-physical), heterogeneity (services are customized), inseparability (services are produced and consumed simultaneously), and perishability (Rathmell 1966; Zeithaml et al 1985; Moeller 2010). Grönroos (2007) describes service as a series of more or less intangible activities that take place during the interaction between the customer and the service provider. An important concern to consumers and producers is how to combine diverse features in design, production and delivery of services in a way that will enhance comparisons and evaluations. Parasuraman (1988)'s SERVQUAL model proposed five key dimensions which customers make use of while evaluating quality: reliability, responsiveness, assurance, empathy, and tangibles. Zeithaml and Bitner (2000) stated that service performance is judged based on the beliefs and expectations of the customer. Parasuraman et al., (1988) suggested that customer expectations are what the customers think a service should offer rather than what might be on offer. A gap arises when the perception of the service delivered and the expectations of the customer do not match. This is addressed by proper implementation of identified strategies that affect perception, expectation or both (Parasuraman et al., 1985; Zeithaml et al., 1990).

The mechanisms organizations put into place to offer the assurance necessary to support this SERVQUAL dimensions is what defines the unique features of the services sector thus service sector organizations have to establish systems that offer basic features that would not only produce and support a service but also provide the means by which customers can make comparisons as well as evaluations on the services and the systems that support the services. This requirement has a bearing on the TMTs and decisions they make.

\subsubsection{Firm Performance}

Firm performance is attributed to the effectiveness of the firm as the myriad of inner performance outcomes normally as a result of more efficient processes and other outside actions that connect to deliberations that are extensive than those naturally allied to economic assessment either by directors, shareholders, or clients such as corporate social responsibility (Dess, 2006; Wachira, 2014). According to Wachira (2014), firms can track and measure performance in several ways such as through financial and non-financial performance indicators of return on investment, return on equity, social and environmental performance. Scholars have described performance in various ways. For example, Johnson (2009) described performance as the procedure of quantification of the competence and efficacy of previous actions including evaluation of how well organizations are managed and the value they deliver to customers and other stakeholders. Similarly, Lewis (2004) categorized main performance indicators in the financial sector into return on equity, market share and growth.

Abu-Jarad (2010) describes the concept of performance as used by scholars as equivalent to the famous 3Es (economy, efficiency, and effectiveness) of a certain program or activity. Javier (2000) described firm performance as the organization's willingness to attain its goals through the optimum utilization of resources. Service sector firm performance is the capacity of the organization to achieve its goals and objectives (Ricardo, 2001).

Firm performance is an integrated strategic approach to improve the effectiveness of the firm by developing the capabilities of the teams and individual contributors in the organization (Armstrong \&Baron, 1998). The primary or secondary sources of information can be a basis for the assessment of service sector firm performance as indicated by 
both financial and non- financial performance. Kaplan and Norton (1993) balanced scorecard is an effective tool for measuring firm performance. In addition, the tool is viewed as innovative and holistic approach towards organizational performance measurement (Andreadis, 2009). Therefore, it is not only possible to measure performance through a balanced scorecard but also easier to manage the firm. The balanced scorecard is an important tool for performance appraisal since it incorporates the financial, customer, internal processes and innovative and learning perspective.

\subsubsection{Conceptual Issues}

The reviewed literature is rich in content as it has explained the constructs of TMT diversity, decision quality and service sector firm performance. This literature is of importance to the advancement of scholarly work in strategic management in the area of TMT diversity and firm performance, especially in the service sector. The construct of TMT has been operationalized using demographic diversity (e.g functional, Education, average tenure and age), cognitive diversity (e.g intuition, feeling, sensing and strategic thinking) and behavioural diversity (e.g values, beliefs and personality traits). Decision quality is a comprehensive and extensive measure of outcome of a strategic decision. The variable has been operationalized using decision comprehensiveness (e.g. shared commitment and team pride), decision extensiveness (e.g. realistic and unrealistic decisions) and group processes (e.g. behavioural integration, task conflict and open communication). Firm performance on the other hand is an integrated strategic approach to improve the effectiveness of the firm by developing the capabilities of the teams and individual contributors in the organization. The variable has been operationalized using financial performance (e.g. return on equity and number of service referrals) and service quality (e.g. tangibility, reliability, assurance, empathy, responsiveness).

A close scrutiny on the empirical studies undertaken by researchers has given insight on how the constructs have been understood and used in strategic management research. Irungu (2007) in his study of TMT demographic diversity on firm performance found out that TMT demographic diversity has no significant positive effect on firm performance while Zahoor (2016) examined the relationship between gender diversity and firm profitability and found out that female executives drive organizations into the positive direction leading to profitability. Tanikawa, Kim and Jung (2017) examined the moderating effect of age on the link between TMT diversity and firm performance in Japan. It was found that TMT age has a negative positive effect on ROE and ROA; Yohannes and Ayako (2016) examined the connection between demographic diversity to firm performance using generic strategy as a moderating variable and found that demographic diversity has a positive effect on performance. Further Meissner and Wulf (2015) assessed the role of decision quality on perceived uncertainty and found out that decision quality influences the level at which firms will perform while George and Desmind (2016) investigated the predictors of strategic decision quality in public organization in Belgium.

\subsection{Theoretical Review}

The extant literature on the conceptual discussion has paid keen attention to how the key constructs of TMT diversity, decision quality and service sector firm performance have been conceptualized. The discussion has brought a number of issues that call for an examination of the relevant theories to explain the phenomenon.

\subsubsection{The Upper Echelons Theory}

The construct of top management team of the firm is anchored on the upper echelon theory developed by Hambrick and Mason (1984). This theory provided a framework in which the TMT demographics can influence the organizational outcomes through their actions and how demographics have been operationalized. Key postulates of the upper echelons theory are the organizations outcomes and strategic choices partially predicted by top management demographics. Management choices do not follow the rational motives but to a large extent are influenced by the natural limitations of managers as human beings (Nielsen, 2010; Usdiken, 1992; Liang, Ndofor, Priem \& Picken, 2010). The manner in which organizations respond to and align themselves with the environment (Machuki \& Aosa, 2011; Andersen, 2004) is what assures the competitiveness and sustainability of an organization. According to the theory, top management demographics include age, education, functional background and financial positions. Other researchers have also included tenure (Nielson and Nielsen, 2013) and gender (Marimuthu \& Kolandaisamy, 2009) as part of what comprises top management demographics. The proponents of the upper echelons theory posit that firms with young managers were driven to make risky decisions than those with experienced managers and that, organizations with younger managers were able to experience growth and profitability. This position was supported by other researchers who argued that younger managers tended to be related to organizational performance due to the fact that they were receptive to change (Hambrick 1994; Tihanyi, Ellstrand, Daily \& Dalton, 2000). An organization that has TMTs with diverse tenure, benefits from the different experiences and perspectives brought by the individual TMTs and this positively affects performance. On education, 
the theory argued that education is an individual's knowledge and skill base and was the foundation of understanding the organizational goals among TMTs. The theory was used to guide the conceptualization of the top management team to service sector firm performance.

\subsubsection{Resource Based View Theory}

The resource-based view (RBV) theory of the firm is a popular theoretical foundation for many studies seeking to improve performance of their organizations (Newman, 2014). The RBV theory postulates that if an organization is to achieve competitive advantage more so within the service sector, it must be able to possess unique resources which are valuable, rare, inimitable, and non - substitutable (VRIN) and be able to take advantage of their capabilities (Kraaijenbrink et al., 2010). RBV proposes that firms with excess productive resources can diversify for purposes of generating more revenue (Montgomery, 1994). The greater the connection between different markets that firms compete, the greater the willingness to share resources across business units leading to improved performance of firms

Several studies have suggested a sequential association among various markets that a firm decides to engage in considering its resource profile specifically the physical, intangible and financial resources (Chatterjee \& Wernerfelt, 1991). The weakness of the RBV is that the RBV viewpoint has a weakness in the sense that it does not escape the general problem of finding the appropriate unit of analysis (Foss, 1998). In contrast, if there is a relationship between complementarity and co-operation between resources, it will be the way resources are clustered and how they interplay and fit into the system that is important to the understanding of firm performance. The foundation of a firm is on its resources necessary for the long term strategy since they provide the road map for the firms anticipated profits. The RBV theory suggests that the pool of resources and capabilities a firm possess is important for the type of diversification strategy it can adopt.

From the extant literature, TMT diversity is an important resource since its optimum level is of value to the firm, very rare to find, seriously difficult to replace and difficult to imitate because of the appropriate mix which matters not the level of capabilities (Barney, 1991; Carpenter, Sanders, \& Gregersen, 2001; Hitt, Bierman, Shimizu, \& Kochhar, 2001). Substitution will come at a cost because of the overall complexity of the team not individuals within. Consequently, TMT diversity is a discrete knowledge based resource not system based resource. Therefore, in theorizing, discrete knowledge based resources can be converted into systemic knowledge based resource by effectively complementing them to the greater contribution of the organizational performance through inter-functional coordination (Eisenhardt \& Martin, 2000; Teece, Pisano, \& Shuen, 1997).

\subsubsection{Stakeholder Theory}

The theory was developed by Freeman (1984). The theory postulates that management pays attention to the interest of the stakeholder's views by regularly listening to their suggestions in regard to how the organization can be managed towards performance (Freeman, 1984). TMTs should model a way in which they are supposed to regularly consult and work closely with various stakeholders within the service sector.

Kakabadse, Rozuel and Davis (2005) examined the role of business in the society and the stakeholder approach is grounded on the level of corporate social responsibility (CSR). Stakeholder theory in business is further supported by Lantos (2001) and Moir (2001) who claim that business people are simply using the means of the principle they are serving leading to a disservice to society which accepted them. Carroll (1991) expresses that there is a close association on companies carrying out regular corporate social responsibility to the society and the organizational shareholders. The success of the organization depends on how healthy the organization has a relationship with its shareholders including the society and other important community organizations within which it operates (Robins, 2008).

Top management team has a responsibility to listen to the various groups, align their views with the overall organizations objectives so as to collectively maximize their suggestions gradually (Freeman \& Philips, 2002). Critics have found stakeholder's theory as a failure, because it does not help the management to clearly identify the stakeholders of a company (Heugens \& Van Oosterhout, 2002). Secondly, the theory is not providing a clear guideline on how to deal with different interests at the same time since every stakeholder's interest should be given equal attention (Nesvadbora, 2010). Therefore, the study finds relevance in stakeholder theory because the TMTs in their duty towards service sector firm performance are not operating in a vacuum but are answerable to different stakeholders. 


\subsubsection{The Attention-Based View of the Firm}

This is defined as the organizational way of focusing their attention on the decision making within the firm (Cohen \& March, 1972; Cyert \& March, 1963; March \& Simon, 1958). The standpoint portrays firms as systems of structurally distributed attention. Further, it claims movements of decision-makers which are the TMTs and the organizational changes are dependent on their attention. Attention is described as "the noticing, encoding, interpreting, and focusing on time and effort" on matters affecting the firm so as to find a solution to problems (Ocasio, 1997).

These problems can emanate from the information obtained from the changing business environment and the available alternative actions in place (Ocasio, 1997; Weick, 1979). However, the decision makers in the organization can solely attend to limited set problems to get answered and these issues will influence their decisions (Ocasio, 1997; Simon, 1947/1997). Careful focus of attention can result into the situation whereby the decision makers can knowingly or unknowingly neglect relevant information necessary for decision making and the available alternatives to the solution (Barnett, 2008; Yates, Jagacinski, \& Faber, 1978). Among the most prominent outcomes of attention having been addressed by research so far are subsidiary performance, strategic change, reaction to external environmental threats, search for innovations and opportunities, timing of product market entry and investments in and adoption of new technologies as well as innovations (Kaplan, 2008; Yadav, Prabhu, \& Chandy, 2007; Hambrick, 2006). However, these works have merely studied attention in isolation without respecting other individual-level factors besides it. This might be a major gap in the attention-based view since attention is not sufficient to make use of opportunities; instead, a comprehensive account on individual's behavior requires taking other behavioural factors into account, especially their ability und motivation (Barnett, 2008; Blumberg \& Pringle, 1982; also see Schijven \& Hitt, 2012; Turner \& Pennington, 2014). The theory is linked to the construct of decision quality since it addresses issues on the overall decision making process of the organization. From the discussion, we can be able to extract the following antecedents of decision making perspective namely attention focus, decision speed and decision comprehensiveness which can serve as operational indicators of decision quality.

\subsubsection{Institutional Theory}

In order to provide meaning and stability to the social life especially in the service sector, institutional theory is described as a social structure that comprises of normative, regulative and social -cultural cognitive stability elements (Scott, 2001). According to Scott $(1987 ; 2001 ; 2008)$, the regulative elements include laws and regulations on governance and power system, while the ordinary elements include values and expectation on the system authority. Finally, the cultural-cognitive elements include similarity in structure and values.

Firms are embedded in their own internal environments like the structures, systems and practices. The external environment, which firms compete with other organizations operating in the industry and the country (Chizema \& Buck, 2006). The institutional perspective for firm behavior states that organizations will attempt to respond to both market and institutional pressures. These pressures force organizations to attempt to incorporate norms from the institutional environment to gain legitimacy in the society. DiMaggio and Powell (1983) refer to this change in organizational behavior as isomorphism; a process through which organizations attempt to resemble the practices of other similar organizations. The institutional theory perspective in the study allows us to analyze the strategic choices made by the organization in the light of the government control in the service sector.

\subsubsection{The SERVQUAL Model}

The model was introduced by Zeithaml, Berry, and Parasuraman (1988) as a tool for evaluating the expectations and perceptions of customers towards service quality. SERVQUAL model has been used as a standardized tool that applies across a broad range of services. The model postulates that customers evaluate service quality based on the comparison between the perception of the service and the individual expectation. In the context of the service sector, SERVQUAL model lies under the five dimensions: reliability, tangibles, responsiveness, assurance and empathy.

Out of five dimensions, 22 statements are derived and measured on both the expectations and perceptions of respondents towards the quality of services the firm is providing. On a 5-point Likert scale, respondents are required to rate the service provider on the extent to which they provide excellent service to its customers. In addition, identical scale is used by the respondents to rate the actual quality of service delivered by the organization based on their perception. For every individual statement made, the difference between perception and expected is measured and the average scores obtained will be the SERVQUAL score (Parasuraman et al., 1988). The 5 measurements of the SERVQUAL model are: Tangibles (the physical resources of the firm), Reliability (the firms capability to perform its services accurately), and Responsiveness (the extent to which the firm is ready to provide quick service), Empathy (attention based customer service by the firm), Assurance (the ability of the employees to inspire trust and 
confidence to customers). In advancing the model, SERVQUAL was modified to SERVPERF in 1992 to measure performance based on quality. The model used the attributes of the 5 dimensions above, worded the same as SERVQUAL but does not repeat the set of statements as expectation items. In light of the explanation given, the model is used by top managers to deploy resources for the purpose of improved firm performance (Wisniewski, 2001).

\subsubsection{Theoretical Issues}

The reviewed theories have raised a number of issues. First, the different proponents of the theories brought out the areas of convergence in their perspectives to the various constructs and phenomenon of strategic management. There are potential areas of complementarities identified which offer potential opportunities for theorizing in conceptual and empirical work in TMT diversity, decision quality and service sector firm performance. For example in considering the postulates of institutional theory vis-a-vis attention based view of the firm, the institutional theory described firms as being embedded in their own structure, system and practices, attention based view of the firm portrays firms as systems of structurally distributed attention. The RBV theory postulates that if an organization is to achieve competitive advantage more so within the service sector, it must be able to possess unique resources which are valuable, rare, inimitable, and non - substitutable (VRIN) and be able to take advantage of their capabilities while the upper echelons complements the theory by having a diverse top management team with unique characteristics capable of utilizing of utilizing resources in a way that they will enable the organizations to achieve performance. However, RBV offers very little explanation on the role of the external environment in achieving competitive advantage using resources. The upper echelons underscore the importance of the construct of TMT diversity encompassing both the observable and cognitive characteristics. The literature connecting environmental factors and demographic characteristics of the top management team is still in its infancy stage (Dalton, 2006).

Secondly, previous empirical attempts have used some of these theories to guide conceptualization in strategy research. For example Yohannes and Ayako (2016) used the RBV theory to expound on the use of generic strategy as an intervening variable on the relationship between top manager's demographic diversity and firm performance in Kenya. Zahoor (2016) used upper echelons and institutional theory to assess the relationship between top management team gender diversity and firm's profitability in Pakistan. Guo, Pang and Li (2017) examined a threshold effect on the meaning of top management team diversity and firm performance of business model innovation in China using upper echelons theory. Ejimabo (2015) used stakeholder view to examine the influence of decision making in organizational leadership and management activities in USA. Finally, Tanikawa, Kim and Jung (2017) used upper echelons and institutional theory to examine the moderating role of age on the relationship between top management team diversity and firm performance in Tokyo, Japan. What however emerges from these previous empirical attempts is the fact that the researchers applied a diversity of concepts that go beyond the constructs in this study sending the message that there is need for consideration of how the concepts can be modeled to inform a strategic management phenomenon from a multidisciplinary perspective.

\section{The Call for a Theoretical Model}

The discussions so far presented have pointed to a number of issues that raise the need for a new theoretical model. First, there are conceptual issues that emanate from the operational indicators to the constructs drawn from the conceptual and the theoretical understanding of TMT Diversity, Decision Quality and Service Sector firm performance. Secondly, in considering the strategic management phenomenon brought about by these constructs, it becomes necessary to understand the role of each in the phenomenon so as to provide an avenue by which future empirical attempts may be conceived and mounted. Arising from (2) above is the need for a systematic and coherent manner in employing the constructs that integrate the theories and practical experience from empirical work to advance the extant knowledge into new frontiers. This requires that researchers develop new theoretical models upon which propositions at the abstraction level can be advanced and empirically tested as hypotheses in empirical work. Scholars have often resorted to basics of ontology and epistemology in addressing debates on how to advance knowledge in a manner that conforms to the scientific methodology.

Nachmias and Nachmias (2004) define scientific methodology as the laid down rules and procedures upon which a scientific research is grounded and against which claims for knowledge are evaluated. It is evident that the system is not unchangeable or without mistakes rather the rules and procedures are constantly being improved; scientists look for new means of observations, analysis, logical inference and generalization. The methodology of social science has evolved slowly. Within this evolution, the continuous interchange of ideas, information and criticism made it possible to firmly establish or institutionalize commonly accepted rules and procedures, such as rules for reasoning, and to develop corresponding methods and techniques. The process places special attention to the role of a theory in 
advancing scientific knowledge. Even though there are debates as to the exact place of theory in research, before or after, there has not been an argument against the use of theory in research. Scholars leaning on this scientific base have used the opportunity to propose theoretical models for informing the direction for future research. For example, Wandiga, Kilika and James (2017) relied on this perspective to propose a new theoretical model for linking operations strategy with performance in a knowledge intensive sector. Fawcett and Downs (1986) describe the components of theory analysis as diagrams depicting the connections between conceptual model and empirical indicators. Theory is formulated this way so that it links concepts to operational definitions and both of these to empirical indicators. Theory is a way of making sense of practice by providing connections. This is why theorizing becomes less ambiguous as one moves from a domain classification through constructs and operational definitions to propositions which explain research findings.

\subsection{Proposed Theoretical Model}

Based on the extant theoretical and empirical literature, the study proposes the following theoretical model/framework. The antecedent factor in the phenomenon involved in the proposed theoretical framework is TMT diversity, while the intermediate state is decision quality and the ultimate state is service sector firm performance. The model also brings in the role played by the institutional environment as the contingent factor influencing the phenomenon. The proposed theoretical framework proposes a number of relationships that are considered critical in understanding the phenomenon for purposes of theorizing, empirical work and practice in strategic management.

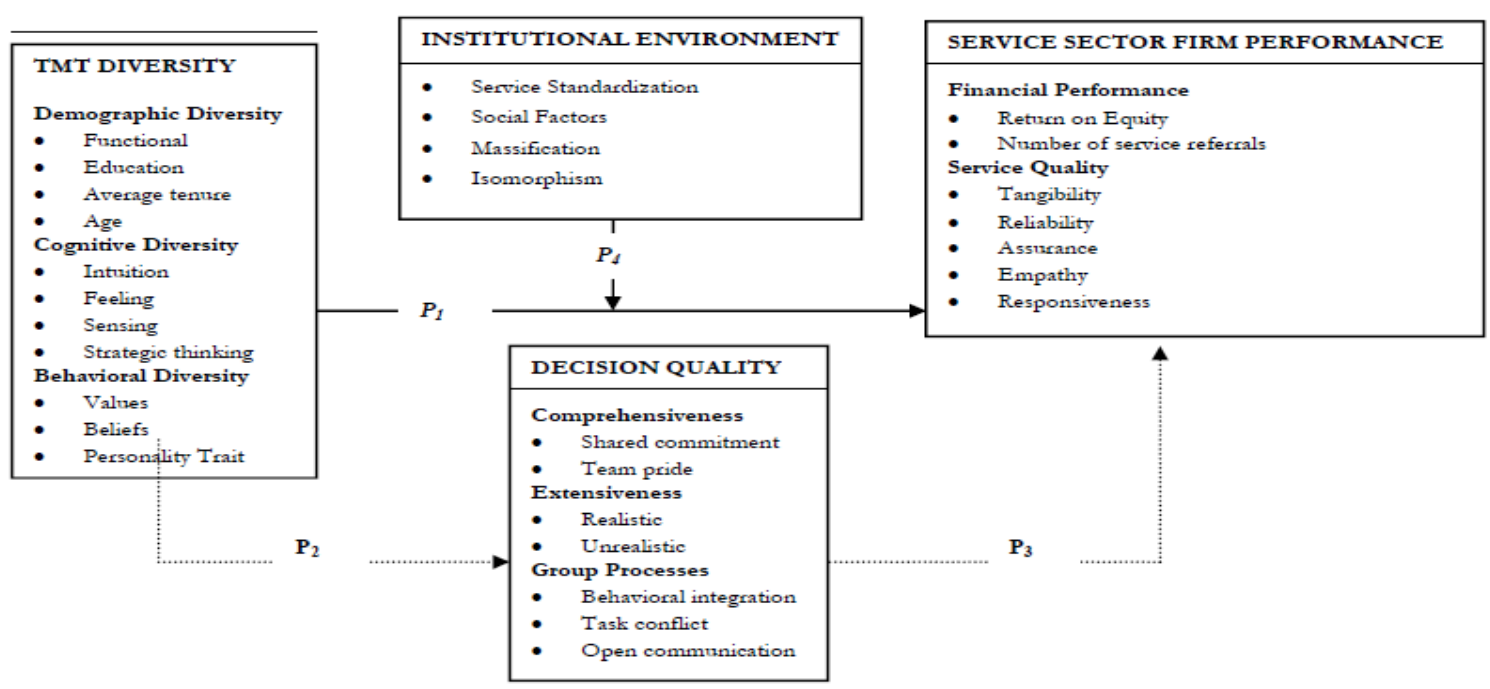

Figure 1. Theoretical model linking TMT diversity, decision quality and service sector firm performance

\subsection{TMT Diversity and Service Sector Firm Performance}

TMT diversity as a construct in strategic management process has been argued to play a role in the performance of organizations. Most of the researches have operationalized TMT diversity in terms of three dimensions, namely: demographic diversity whose indicators are age, team tenure, level of education, functional experience; cognitive diversity which is operationalized through feeling, sensing, strategic thinking, intuition; and behavioral diversity which has been operationalized using the values, beliefs and personality traits of TMT members in the firm (Kinuu, 2014). The upper echelons perspective to empirical research posits that TMTs with a diverse team have an impact on the social dynamics of team members including frequency of communication among the team members, communication effect, degree of integration and coherence, thereby influencing organizational performance. In addition, research has proven that TMT diversity has a positive effect on firm performance because of the strong problem solving ability that the team possesses (Muchemi, 2010). Service sector firm performance been operationalized using indicators such return on investment, number of service referrals, network strength, tangibility, reliability, assurance, responsiveness and empathy (Campbell, 2007; Parasuraman, 1988).

In view of the reviewed theoretical and empirical literature that TMT translates policies into goals, objectives, strategies and projects meant to steer the organization to success both in the present and future, it is worthwhile to 
conclude that TMT diversity brings into an organization a capability that has potential to enhance the performance of the firm (Haleblian \& Finkelstein, 1993). For example, demographic diversity attributes like education, functional, average tenure and age can usher into the organization a strategic thinking capability that is likely to give the organization an enhanced impetus to realize better performance in a number of ways such as better utilization of resources, team working, networking with the market. In addition, Demographic diversity may usher advantages such as enhanced objectivity, comprehensiveness, logical predictive power, and its testability (Bolo, Muchemi \& Ogutu, 2011). From the extant literature demographic diversity has been shown to influence team processes, such as behavioural/social integration, task conflict and open communication, and this in turn affect firm performance within the service sector (Awino, 2012). The presence of the TMT members with differing points of views on issues at hand within the service sector leads to a larger set of potential alternative solutions through comprehensive group discussions leading to service sector firm performance. Cognitive diversity that has been operationalized through intuition, feeling, sensing and strategic thinking may bring into the organization a more strategically aligned perspective that can achieve a better fit in the context resulting to a better response to market and other environmental demands. Behavioural diversity operationalized through values, beliefs and personality traits of the TMT members can enhance ability to make choices that can enhance the performance of firms. Based on these arguments, we thus propose that:

Proposition 1: The dimensions of TMT Diversity when deployed in a strategically oriented service sector firm, TMT Diversity will have a significant influence on the performance of service oriented firms

\subsection{The Role of Decision Quality}

While the TMT diversity serves the role of the antecedent factor in the phenomenon linking TMT Diversity with firm performance, the intermediate outcome of such diversity on the path to influencing the performance of the firm becomes that of decision quality. The construct of decision quality is operationalized through decision comprehensiveness and extensiveness through shared commitment, team pride, realistic and unrealistic decisions (Carmeli, Sheaffer \& Halevi, 2009). Well constituted and properly functioning TMTs in organizations are expected to demonstrate consciousness and sensitivity to their strategic role in not only setting the future direction of the firm but also steering the firm towards the realization of that direction. They will therefore exercise due diligence and caution in the nature, type and manner of decision making so as to optimize the opportunities availed to the firm by the developments of the contexts within which the firms strategic decisions have to be made and executed. Thus, it is logical to argue that: TMT diversity will lead to a decision making process that will enhance decision quality as a necessary condition that the organization requires in order to assure continued sustained performance. Thus the paper proposes that:

Proposition 2: TMT Diversity in strategically oriented service firms will lead to an intermediate state of capability in the form of high level of decision quality as a necessary condition for sustaining the desired firm performance.

The generated level of decision quality may be viewed as a form of competence that the service sector firm realizes as an immediate benefit from the deployment of TMT Diversity dimensions. If the TMT Diversity is considered a form of a resource using the RBV lens, then out of this resource, organizations are able to generate intermediate outcomes that can be construed to refer to a state of capability or competence that is manifested through high levels of decision quality. Such a capability is considered a vital distinguishing feature of a firm suitable to guarantee sustainability of a firm's performance. Thus, the authors are of the view that this generated form of competence is a necessary requirement for firms to rely upon to sustain their performance. The paper thus proposes that:

Propositions 3: Even though TMT Diversity will influence the performance of the service sector firm, the strength of such a relationship will be dependent upon the high level of Decision Quality generated from the deployment of TMT Diversity dimensions.

\subsection{The role of the Institutional Environment}

The phenomenon depicting TMT Diversity, Decision Quality and Firm Performance in a strategic management perspective is one that comes into contact with the forces of the external context of the firm. One of the defining characteristics of strategic decisions is that of the role of the external environment in influencing not only firm's decisions but also the strategic behavior exhibited by the firm in its context. For service oriented firms, one of the concerns that arises from the nature of services is that of standardization that may raise the need for firms to conform to certain norms, societal and market expectations so as to attain legitimacy in that specific context. Service sector firms therefore need to be alert to the requirements of the institutional setting of the contexts in which they operate. The Institutional perspective to the sociology of organizations highlights some of the pressures for conformity such as 
diverse forms of isomorphism, societal values and norms. Since the conformity may win the firm legitimacy in the eyes of the society, such a legitimacy will be critical in determining the success of the outcomes of the TMT Diversity deployment. Thus the paper proposes that:

Proposition 4: The level of influence of TMT Diversity on service sector firm performance is contingent upon the firm's level of conformity to the institutional environment faced by the service sector firm.

\section{Conclusion and Suggestion for Further Research}

This paper sought to review the state of the theoretical and empirical literature on the constructs of TMT Diversity, Decision quality and service sector firm performance. The paper presented a conceptual review of the diversity in the current understanding of the constructs and identified the theoretical underpinnings to the constructs. The various studies undertaken to practically demonstrate how these constructs have been applied and operationalized were explored. The emerging gaps in knowledge have been identified and a theoretical model linking the constructs proposed. Based on the flow of relationships in the proposed model, a number of propositions that are suitable to guide future research have been suggested. Since the propositions have not yet been tested using primary data, the authors call on future research to undertake empirical work based on the constructs proposed in this paper in order to test and validate these propositions. Such initiatives would require that the researchers use the indicators to the constructs in the proposed theoretical model to develop a primary data collection instrument that would obtain primary data from relevant samples.

\section{References}

Awino, Z. B. (2013). Top Management Team Diversity, Quality Decisions and Organizational Performance in the Service Industry. Journal of Management and Strategy, 4(1), 113-124. https://doi.org/10.5430/jms.v4n1p113

Beckman, C. M., \& Burton, M. D. (2011). Bringing organizational demography back in: Time, change and structure in top management team research. The Handbook of Research on Top Management Team. Edward Elgar Publishing.

Bolo, A. Z., Muchemi, A. W., \& Ogutu, M. (2011). Diversity in the top management teams and effects on corporate performance. Business Administration and Management, 1(3), 82-92.

Carmeli, A. (2008). Top management team behavioral integration and the performance of service organizations. Group Organization Management, 33(6), 712-735. https://doi.org/10.1177/1059601108325696

Carpenter, M. A. (2002). The implications of strategy and social context for the relationship between top management team heterogeneity and firm performance. Strategic Management Journal, 23, 275-284.

Carpenter, M. A., Geletkanycz, M. A., \& Sanders, W. G. (2004). Upper echelons research revisited: Antecedents, elements, and consequences of top management team composition. Journal of Management, 30(6), 749-778. https://doi.org/10.1016/j.jm.2004.06.001

Certo, S. T., Lester, R. H., Dalton, C. M., \& Dalton, D. R. (2006). Top management teams, Strategy and financial performance: A meta-analytic examination. Journal of Management Studies, 43(4), 813-839. https://doi.org/10.1111/j.1467-6486.2006.00612.x

Clark, K. D., \& Maggitti, P. G. (2011). Top management team confidence. The Handbook of Research on Top Management Team. Edward Elgar Publishing. https://doi.org/10.4337/9780857933201.00014

Dezs, C. L., \& Ross, D. G. (2012). Does female representation in top management improve firm performance? A panel data investigation. Strategic Management Journal, 33, 1072-1089. https://doi.org/10.1002/smj.1955

Don, K., Craig L., Pearce, K. G., Smith, J. D., Olian, H. P., Ken, A. S., \& Patrick F. (1999). Top management team diversity, group process, and strategic consensus. Strategic Management Journal, 20(5), 445-465.

Finkelstein, S. (1992). Power in top management teams: dimensions, measurement, and validation. Academy of Management Journal, 35(3), 505-538. https://doi.org/10.2307/256485

Finkelstein, S., \& Hambrick, D. C. (1996). Strategic leadership: Top executives and their effects on organizations. Minneapolis: West Publishing.

Forsyth, D. R. (2006). Group dynamics. International Student Edition. Belmont CA: Thomson Wadsworth Publishing.

Frankfort-Nachmias, \& Nachmias, D. (2004). Research methods in the social sciences (English). New York, NY: St. Martin's Press. 
Friedman, M. (1970). The social responsibility of business is to increase its profits. N.Y. Times, 6(30), 126-127.

Gist, M. E., Locke, E. A., \& Taylor, M. S. (1987). Organizational behavior: Group structure, process, and effectiveness. Journal of Management, 13, 237-257. https://doi.org/10.1177/014920638701300204

Gladstein, D. L. (1984). Groups in context: A model of task group effectiveness. Administrative Science Quarterly, 29, 499-517. https://doi.org/10.2307/2392936

Gomez-Haro, S., Aragon-Correa, J., \& Cordon-Pozo, E. (2011). Differentiating the effects of the institutional environment on corporate entrepreneurship. Management Decision, 49(10), 1677.

Hambrick, D. C. (2007). Upper echelons theory: An update. Academy of Management Review, 32(2), $334-343$.

Hambrick, D. C., \& Mason, P. (1984). Upper echelons theory: The organization as a reflection of its mangers. The Academy of Management Review, 9(2), 193-206.

Hambrick, D. C., Humphrey, S. E., \& Gupta, A. A. (2014). Structural interdependence within top management teams: A key moderator of upper echelons predictions. Strategic Manegement Journal, 36(3), 449-461.

Irungu, M. S. (2007). The effect of top management teams on the performance of publicly Quoted companies in Kenya. Unpublished PhD Thesis. University of Nairobi.

Kaplan, R., \& Norton, D. (1992). The balanced scorecard: The measures that drive performance. Harvard Business Review, 7(1), 71-79.

Kostova, T., \& Roth, K. (2002). Adoption of an organizational practice by subsidiaries of multinational corporations: Institutional and relational effects. Academy of Management Journal, 45(1), 215-33.

Lee, M. D. (2008). A review of the theories of corporate social responsibility: Its evolutionary path and the road ahead. International Journal of Management Reviews, 10(1), 53-73.

Li, J., \& Hambrick, D. C. (2005). Factional groups: A new vantage on demographic fault lines, conflict, and disintegration in work teams. Academy of Management Journal, 48(5), $794-813$. https://doi.org/10.5465/AMJ.2005.18803923

Lin, Y., \& Wang, D. (2014). The impacts of top management team characteristics on entrepreneurial strategic orientation: The moderating effects of industrial environment and corporate ownership. Management Decision, 52(2), 378-409. https://doi.org/10.1108/MD-03-2013-0140

Machuki, V. N., \& Aosa, E. (2011). The influence of the external environment on the Performance of publicly quoted companies in Kenya. Business Administration and Management, 1(7), 205-218.

Marimuthu, M., \& Kolandaisamy, I. (2009). Can demographic diversity in top management team contribute for greater financial performance? An empirical discussion. The Journal of International Social Research, 2(8), $273-286$.

Muchemi, W. A. (2013). Top management team diversity and performance of commercial banks In Kenya. Unpublished PhD Thesis. University of Nairobi.

Mugambi, G. K., \& K'Obonyo, P. (2012). The predictive value of contextual factors on corporate performance in Kenya. Prime Journal of Business Administration and Management, 2(10), 709-725.

Mutuku, C. (2012). Factors influencing relationship between top management team diversity and performance of commercial banks in Kenya. Unpublished PhD Thesis. University of Nairobi.

Nadkarni, S., \& Herrmann, P. (2010). CEO personality, strategic flexibility and firm performance: The case of Indian business process outsourcing industry. Academy of Management Journal, 53(5), 1050-1073. https://doi.org/10.5465/AMJ.2010.54533196

Nielsen, B. B., \& Nielsen, S. (2013). Top management team nationality diversity and firm performance: A multilevel study. Strategic Management Journal, 34(3), 373-382. https://doi.org/10.1002/smj.2021

Nielsen, S. (2010). Top management team diversity: A review of theories and methodologies. International Journal of Management Reviews, 26(3), 301-316.

Peterson, S. J., \& Zhang, Z. (2011). Examining the relationship between top management team psychological characteristics, transformational leadership, and business unit performance. The Handbook of Research on Top Management Team. Edward Elgar Publishing. https://doi.org/10.4337/9780857933201.00013

Wandiga, E. N., Kilika, J. M., \& James, R. (2017). Linking Operations Strategies with Customer Based Competence and Firm Performance in the Context of Knowledge Based Intensive Sector: A Theoretical Review. International Journal of Business \& Management, 12(8), 234-248. https://doi.org/10.5539/ijbm.v12n8p234 